\title{
Vantagens e desvantagens da citologia convencional e da citologia em meio líquido na prática clínica: uma revisão integrativa da literatura
}

\author{
Advantages and disadvantages of conventional cytology and liquid-based cytology in clinical
} practice: an integrative literature review

Ventajas y desventajas de la citología y citología convencionales en medio líquido en la práctica clínica: una revisión integrativa de la literatura

\begin{abstract}
Resumo
A citologia convencional é um método de coleta e análise de tecido cervical criado em 1928 como exame preventivo para o câncer de colo do útero, e embora o melhor método encontrado até o momento, haviam problemas quanto à precisão do exame e alta taxa de falsos-negativos. Em 1991 Martha L. Hutchinson cria a citologia em meio líquido, técnica que pretendia mitigar essas falhas. Este artigo faz uma revisão integrativa da literatura sobre citologia convencional e citologia em meio líquido, comparando as vantagens e desvantagens de cada um dos métodos de análise. Estão presentes artigos, monografias, dissertações e teses em português publicados entre 2016 e 2021 nos repositórios google acadêmico, scientific electronic library online (Scielo), pubmed e scopus que tenham as palavras-chave "citologia convencional", "citologia em meio líquido", "citologia convencional e citologia em meio líquido" ou "citologia em meio líquido e citologia convencional", sendo encontrados cinco artigos sobre o tema dentro desses parâmetros. Conclui-se que a citologia em meio líquido apresenta novas potencialidades para a citologia, mas a convencional possui valor específico na simplicidade do método que permite que ele seja realizado sem estrutura complexa, fazendo deste método confiável e valioso o suficiente para não ser tido como obsoleto.
\end{abstract}

Palavras-chave: Citologia; Câncer de colo do útero; HPV.

\begin{abstract}
Conventional cytology is a method created in 1928 for collecting cervical tissue as a preventive exam for cervical cancer, and even being the best method to do so then, it had flaws and a high rate of false-negatives. In $1991 \mathrm{Martha}$ L. Hutchinson creates liquid-based cytology, technique that intended to mitigate this problems. This paper does an integrative literature review about conventional cytology and liquid-based cytology, comparing the advantages and disadvantages of each one of the analysis methods. The analyzed papers are journal articles, monographies, dissertations and thesis written in Portuguese between 2016 and 2021 that were found in scholar google, scientific electronic library online (Scielo), pubmed and scopus and had the keywords "citologia convencional", "citologia em meio líquido", "citologia convencional e citologia em meio líquido" or "citologia em meio líquido e citologia convencional”, being found five papers in the said parameters. It is concluded that liquid-based citology presents new potentialities to cytology, but the conventional one has a specific value in the simplicity of the method which requires no complex structures, making it efficient and trustworthy enough to justify it not being obsolete.
\end{abstract}

Keywords: Cytology; Cervical cancer; HPV.

\section{Resumen}

La citología convencional es un método para recolectar y analizar tejido cervical creado en 1928 como un examen preventivo del cáncer de cuello uterino, y aunque el mejor método encontrado hasta ahora, hubo problemas con la 
precisión del examen y una alta tasa de falsos negativos. En 1991 Martha L. Hutchinson creó la citología en medio líquido, una técnica que pretendía mitigar estos defectos. Este artículo realiza una revisión integradora de la literatura sobre citología convencional y citología líquida, comparando las ventajas y desventajas de cada uno de los métodos de análisis. Hay artículos, monografías, disertaciones y tesis en portugués publicados entre 2016 y 2021 en google académico, biblioteca electrónica científica en línea (Scielo), repositorios pubmed y scopus con las palabras clave "citologia convencional", "citologia em meio líquido", "citologia convencional e citologia em meio líquido" ou "citologia em meio líquido e citologia convencional", encontrándose cinco artículos sobre el tema dentro de estos parámetros. Se concluye que la citología de base líquida tiene un nuevo potencial para la citología, pero la citología convencional tiene un valor específico en la simplicidad del método que permite realizarla sin una estructura compleja, lo que hace que este método sea lo suficientemente confiable y valioso como para no ser considerado obsoleto.

Palabras clave: Citología; Cáncer de cuello uterino; VPH.

\section{Introdução}

A citologia cérvico-vaginal é um método de análise das células cervicais desenvolvido por George Nicholas Papanicolaou durante as décadas iniciais do século XX e formalizada em estudo publicado em 1928, apresentando a técnica que tem base na coleta de uma amostra de células uterinas a partir da escovação, permitindo analisar essas células em laboratório e fazer um diagnóstico de lesões precursoras e do próprio câncer de colo uterino (Zonta, 2019).

Contudo, em 1991 Martha L. Hutchinson tenta aprimorar a técnica utilizando a tecnologia desenvolvida desde a criação do exame citológico convencional. A citologia em meio líquido é uma técnica que usa novos processos para a análise da amostra: na coleta por esfregaço da citologia convencional por volta de $80 \%$ do material coletado é desperdiçado enquanto a citologia em meio líquido utiliza $100 \%$ do material. Isso cria a possibilidade de que em uma só coleta diversas análises podem ser feitas e há uma visualização mais clara do material fixado nas lâminas que não possui células que poluem o campo de visão do analista (Sampaio, 2015; Heise \& Lima, 2016).

O exame preventivo é necessário pois permite que neoplasias sejam detectadas antes de atingirem o grau de desenvolvimento para câncer de colo do útero, que necessitará então de tratamentos mais agressivos e caros. A prevenção diminui custos, podendo evitar a necessidade de tratamentos e melhorando a qualidade de vida (Oliveira et al, 2011).

Estes métodos constatam lesões precursoras e evidenciam a presença de câncer de colo de útero a partir do contágio pelo Papilomavirus Humano (HPV). Dessa forma, atualmente, há também forte interesse nos esforços por parte dos médicos no sentido de detectar a presença dos diferentes tipos de genótipos virais nas mulheres, uma vez que há alguns tipos muito mais agressivos que outros que com maior chance de avançar para o câncer de colo de útero (Nakagawa et al, 2010).

O presente artigo apresenta os métodos da citologia convencional e da citologia em meio líquido a partir dos textos de Storti Filho e Pereira (2014) e Zonta (2014) e, em seguida, analisa a bibliografia atual produzida sobre o tema, buscando nov as descobertas, desenvolvimentos ou perspectivas acerca dos métodos de análise.

\section{Metodologia}

A metodologia utilizada é a revisão bibliográfica integrativa, sendo essa caracterizada pela integração crítica das diversas discussões que aparecem na literatura selecionada (Crosseti, 2012), buscando artigos, monografias, dissertações e teses em português publicados entre 2016 e 2021 nos repositórios google acadêmico, scientific electronic library online (scielo), pubmed e scopus que tenham as palavras-chave "citologia convencional”, "citologia em meio líquido”, "citologia convencional e citologia em meio líquido" ou "citologia em meio líquido e citologia convencional”, sendo encontrados cinco artigos sobre o tema dentro desses parâmetros. Depois, os textos são analisados segundo três critérios levantados a partir da literatura que aborda a citologia convencional e a citologia em meio líquido: a) quais são as vantagens desse tipo? b) quais são as desvantagens desse tipo? c) Qual o método mais eficaz na prática clínica? 


\section{Discussão e Resultados}

A citologia convencional permite analisar as células em laboratório, fazendo um diagnóstico de lesão precursora e do próprio câncer de colo de uterino. Tem início com a coleta de células cervicais onde, inicialmente, é introduzido um esfregaço no canal vaginal da mulher que é utilizado para coleta de células escamosas (ectocérvice) e glandulares (endocérvice) por meio de uma raspagem da região. Após a coleta, esses tecidos são transferidos direto do esfregaço para lâminas em até 10s e fixados por meio da imersão da lâmina em álcool entre 75 e $90 \%$ de concentração ou spray de propilenoglicol. Isso garante que a morfologia das células não seja alterada, não percam a sensibilidade aos corantes e preserva as contra o ressecamento (Storti Filho \& Pereira, 2014).

Posteriormente as lâminas serão processadas pelo profissional responsável em três fases: pré-analítica, onde há a recepção dos materiais, confirmam-se os registros dos mesmos e é feito o processo de coloração majoritariamente por meio da técnica Papanicolaou, ocorrendo coloração do núcleo e do citoplasma, fases de desidratação, hidratação e diafanização. A fase analítica é iniciada com anamnese a partir da ficha da paciente e seguida pela leitura da lâmina por meio da microscopia sendo que, através da observação, é produzido um diagnóstico. E na fase pós-analítica, elabora-se o laudo para o requerente do diagnóstico e arquiva-se as lâminas (Storti Filho \& Pereira, 2014).

Essa técnica é adotada universalmente nos sistemas de saúde escandinavos, canadenses e estadunidenses para o rastreamento e a prevenção do câncer de colo de útero, a partir de onde se propaga pelo mundo como a mais eficiente técnica para essa finalidade (Franco, 2014). Holanda, Reino Unido e Islândia também adotaram a prática e desenvolveram programas de rastreamento de 20 a 30 anos que foi mantido com a cobertura de $75 \%$ a $80 \%$ das mulheres, o que levou a uma queda que variou entre $17 \%$ a $32 \%$ da mortalidade do câncer de colo de útero nestes países (Heise \& Lima, 2016).

No Brasil, durante a década de 1990, a cobertura nacional de pacientes que passaram pelo procedimento era de 7,7\% (Brito et al, 2007), enquanto os dados coletados pela Pesquisa Nacional por Amostra de Domicílio (PNAD) em 2008 mostram que a cobertura nacional atingiu 79,32\%, evidenciando um forte investimento na universalização da prática nesse período, mas a região norte ainda tinha a segunda menor taxa com 77,61\%, taxa superior apenas ao 74, $09 \%$ do nordeste ${ }^{1}$.

Entretanto, em 1991, Martha L. Hutchinson desenvolveu a citologia em meio líquido, uma inovadora técnica que trazia novas características para a análise celular do procedimento: enquanto na citologia convencional aproximadamente $80 \%$ do material coletado fica preso à escova cervical, sendo desperdiçado, a citologia em meio líquido utiliza 100\% do material coletado, possibilitando que em uma só coleta múltiplas análises sejam feitas e uma visualização menos poluída do conteúdo das lâminas, dada a ausência de muco, hemácias e demais células pela centrifugação da amostra, permitindo ainda que as células estejam dispostas em uma monocamada (Sampaio, 2015; Heise \& Lima, 2016).

Embora semelhante, com objetivo de coletar os mesmos tecidos que o método convencional coleta usando o esfregaço, a citologia em meio líquido tem algumas diferenças já nessa fase em consequência das diferentes necessidades dos métodos de análise (Zonta, 2019).

Na fase de coleta não é usado um esfregaço, mas uma escova de cerdas plásticas com cabeça destacável. A escova é introduzida no canal vaginal até que a parte afilada da ponta da escova é introduzida no orifício externo do canal uterino e, então, é rotacionada $360^{\circ} \mathrm{em}$ sentido horário duas vezes em dois movimentos separados. Após a coleta, a cabeça da escova é destacada e imediatamente depositada dentro do líquido conservante, o que permitirá que a amostra mantenha boas condições para análise citológica e molecular, sendo possível conservá-la em temperatura ambiente por 15 dias, refrigeração de $4^{\circ} \mathrm{C}$ por 6 meses e até 2 anos em $-20^{\circ} \mathrm{C}$ (Zonta, 2019).

\footnotetext{
${ }^{1}$ Dados retirados do IDSUS.
} 
Ao chegar no laboratório, as amostras passam, inicialmente, por um processo de homogeneização seguido por um processo de enriquecimento por centrifugação, aumentando a concentração das células. A dispersão do material no líquido permite que ele seja integralmente utilizado, ao contrário do desperdício apresentado pelo método convencional que, sendo impossibilitado de utilizar todo o material na análise é em grande parte responsável pela ocorrência de falsos-negativos (Zonta, 2019).

Além disso, a "metodologia é capaz de diminuir interferentes, como, por exemplo, o excesso de muco, restos celulares, exsudato inflamatório intenso, hemácias e outros interferentes como espermatozoides e artefatos capazes de mascarar os achados citológicos" (Zonta, 2019, p.45). Sendo assim, o meio líquido apresenta uma maior chance de diagnóstico preciso.

Ademais, ele possibilita a automatização das leituras que auxiliam em larga escala na identificação de alterações celulares, atualmente com a inclusão de inteligências artificiais que aumentam ainda mais a capacidade de auxiliar a leitura do profissional (Matias, 2016, p.92), ajudando o profissional responsável pela análise a realizar o diagnóstico. Em 12 de dezembro de 2019, o Ministério da Saúde por meio da Secretaria de Ciência, Tecnologia, Inovação e Insumos Estratégicos em Saúde outorga a Portaria n ${ }^{\circ} 63$, incorporando a citologia em meio líquido ao Sistema Único de Saúde, atestando a eficácia do método.

Uma vez que o câncer de colo de útero ainda seja muito recorrente na saúde brasileira, estudos sobre os principais métodos de prevenção tenham forte ligação com o interesse público. A taxa é especialmente alta na região norte e, principalmente, no Amazonas: enquanto a média nacional de casos por 100,000 mulheres em 2020 foi de 16,85, no Amazonas ela atinge 33,08, um aumento de 102\% nos casos (Instituto Nacional do Câncer apud Liga Amazonense Contra o Câncer, 2021). É necessário, portanto, compreender como esses dois métodos funcionam e quais são seus potenciais, pois dessa forma é possível que possam auxiliar na diminuição da incidência do câncer de colo de útero.

Martins (2016) analisa a citologia em meio líquido, ou "base líquida", como dito no texto, para detecção do HPV de alto risco em como fator de impacto na prevenção de câncer de colo do útero na rede pública de saúde de São Paulo, além de outros métodos para a deteç̧ão dos diversos de gens. O autor conclui que os testes de HPV são mais eficientes para essa finalidade do que as citopatologias, mas expõe também que "A inclusão da citologia em meio líquido facilita todo processo de coleta, transporte, armazenamento e leitura associada ao uso de computador; além de permitir a associação com testes moleculares" (Martins, 2016, p.115), e que se considerarmos que o "Governo Brasileiro com o objetivo de prevenção do câncer de colo do útero financia mais de 10 milhões de exames de papanicolaou por ano, 3\% de casos insatisfatórios representa aproximadamente a repetição dos exames por 300.000 mulheres" (Martins, 2016, p.92), mesmo pensando em relação a custos e gastos a citologia em meio líquido é mais eficiente.

É importante notar que até mesmo ao trazer o debate para o viés econômico, quando mobiliza-se o custo do método da citologia em meio líquido como um ponto negativo em comparação ao convencional, o autor demonstra que enquanto política de governo talvez seja mais eficiente alocar recursos para um sistema mais caro porém confiável do que um sistema barato mas com alta taxa de coletas insatisfatórias.

A monografia de Rocha (2016) compara empiricamente os métodos de citologia convencional e citologia em meio líquido para diagnosticar as lesões precoces do câncer de colo uterino, usando dados primários da atividade do laboratório em que atua. $\mathrm{O}$ trabalho traz um quadro exploratório amplo com 351 observações, sendo 255 relativas à citologia convencional e 96 à citologia em meio líquido, completando a pesquisa com a apresentação de variados dados específicos produzidos por cada um dos métodos. 
Figura 1 - Adequabilidade de Esfregaços (Citologia Convencional).

\section{Adequabilidade de Esfregaços}

Citologia convencional

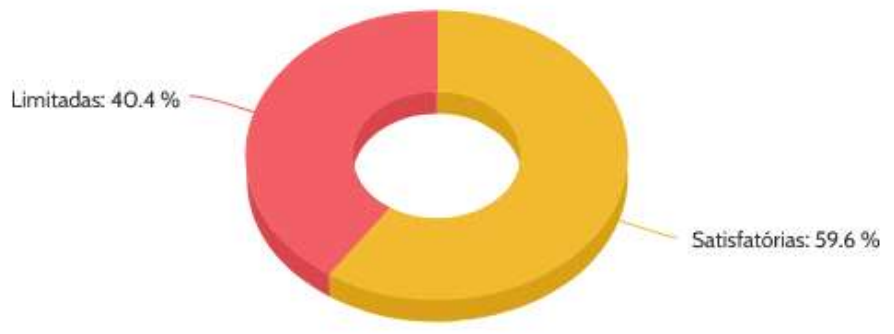

Fonte: Rocha (2016, p.22)

Figura 2 - Adequabilidade de Esfregaços (Citologia em Meio Líquido).

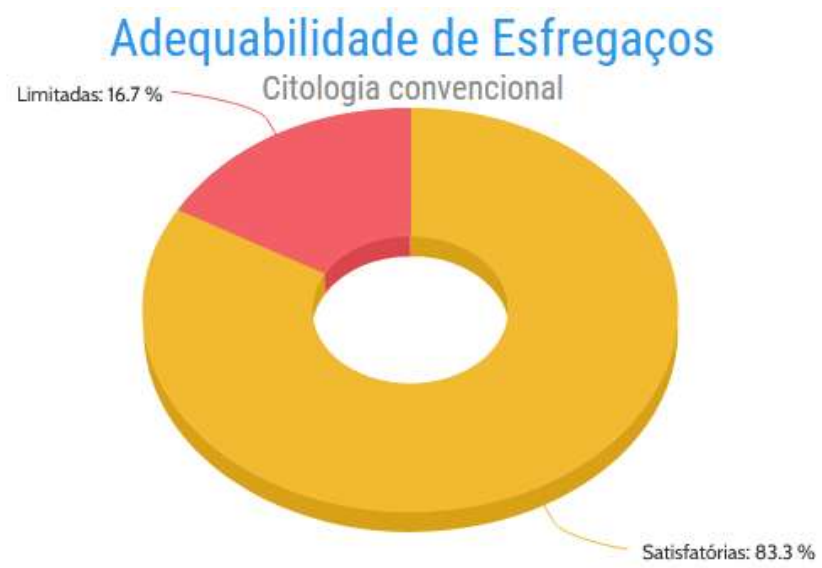

Fonte: Rocha (2016, p.22).

Como esses gráficos mostram, a tendência amplamente citada de um número muito menor de lâminas inadequadas na citologia em meio líquido se manteve. São 59,6\% satisfatórios na metodologia convencional frente a 83,3\% na de base líquida, expondo uma diferença considerável.

Apresenta também outros dados que fogem o escopo do trabalho mas podem ser apresentados para demonstrar a profundidade do trabalho: a quantidade absoluta e em porcentagem dos diagnósticos obtidos a partir de cada um dos métodos; resultados obtidos a partir de biópsias das 351 observações; as divisões de baixo e alto grau detectadas a partir de cada metodologia; a faixa etária das observações que tiveram diagnósticos de lesão de alto grau; a captura híbrida para HPV.

Após farta apresentação de dados e discussão, a autora cita que a citologia convencional mostrou alta sensibilidade para lesões precursoras do câncer de colo uterino $(87,8)$ embora tenha tido uma especificidade baixa (40). Por sua vez, a citologia em meio líquido mostrou sensibilidade mais alta que a convencional $(91,5)$ e uma especificidade mais baixa que a convencional $(21,4)$. Conclui-se então que "A sensibilidade da citologia em meio líquido demonstrou um brando aumento quando comparada com a citologia convencional" (Rocha, 2016, p.34), além da taxa de adequabilidade dos esfregaços ser maior na base líquida.

O texto de Silva et al (2021) busca discutir como três diferentes tipos de método de análise podem contribuir no diagnóstico de lesões cervicais resultantes de infecção pelo papiloma vírus humano (HPV) por meio da coleta de amostras do endocérvice e ectocérvice, tecidos presentes no canal vaginal. Os autores comparam então a citologia convencional, embora 
chamem-na de "Papanicolaou Convencional", a citologia em meio líquido e a captura híbrida por hybrid sérico - CH2, um método de análise específico com células reagentes ao HPV sendo posicionadas junto da amostra inicialmente e, em seguida, expostas a um substrato quimioluminescente da fosfatase alcalina. Os autores dizem então que enquanto o exame de papanicolaou tem baixo custo e permite a identificação de lesões precursoras LSIL (lesão intraepitelial de baixo grau) e HSIL (lesão intraepitelial de alto grau), há elevada taxa de falsos-negativos, o que não ocorre na citologia em meio líquido que permite um aumento da sensibilidade e especificidade da análise, embora com custos mais altos vinculados à necessária infraestrutura.

Concluem então que a citologia em meio líquido é superior à citologia convencional pois apresenta ganho em especificidade e sensibilidade, mas o alto custo, a necessidade por treinamento especializado para a equipe e a necessidade por infraestrutura complexa e sua manutenção elevam os gastos com seu funcionamento. Portanto, apesar de considerarem a citologia em meio líquido tecnicamente superior, o baixo custo e a simplicidade da análise da citologia convencional colocam-na como método que dificilmente será considerado obsoleto.

Monteiro et al (2017) discutem se, apesar das diversas publicações que atestam uma maior eficácia da citologia em meio líquido para rastrear neoplasias no colo do útero, ele é realmente benéfico para o sistema de saúde a nível global, mobilizando também os impactos da introdução do método no mesmo, custos, conhecimento técnico necessário para o método, e outros fatores que impactem em sua inserção. Após descrever objetivamente a história e o funcionamento da técnica, os autores relatam seus benefícios e suas desvantagens.

Os benefícios listados são ditos como, principalmente, decorrentes do armazenamento da amostra no líquido fixador, uma vez que essa característica permite a utilização de uma só amostra para realização de testes histoquímicos e moleculares, além de preservar a morfologia das células, favorece menor número de falsos-negativos e esfregaços insatisfatórios, e o aumento da produtividade dos laboratórios uma vez que a duração dos exames diminui em 30\%.

Além disso, a citologia em base líquida permite a tipagem do Papilomavirus Humano, a mensuração da carga de oncoproteínas virais, o estudo da expressão de biomarcadores do câncer de colo do útero e a identificação da flora vaginal; cita rapidamente que o desempenho do teste de HPV-DNA não pode ser comparado objetivamente com a citologia em meio líquido pela falta de estudos de qualidade sobre as configurações de rastreio. A última vantagem citada é a possibilidade de utilizar a técnica de bloco celular, que permitiria uma maior e mais ordenada coleta de material com cortes seriados de um mesmo exemplar, possibilitando oferecer análises moleculares em estudos de diagnóstico. As desvantagens, por outro lado, são as previamente citadas questões de menor especificidade, maior custo e necessidade de capacitação técnica do pessoal. Essas informações estão sintetizadas na imagem 3.

O texto conclui dizendo que, na realidade, “As publicações atualmente disponíveis não são suficientes para estimar o desempenho relativo dos métodos de CML e CC e não há nenhuma evidência de que a CML seja mais precisa do que a CC na detecção de doença de alto grau" (Monteiro et al, 2017, p.113), fazendo com que seja necessário ao profissional da saúde responsável pela coleta utilizar dos recursos disponíveis conforme cada caso. Além disso, constata que é necessário mais estudos comparativos com experimentos controlados para mensurar as diferenças entre os dois métodos.

Embora a bibliografia anteriormente escrita, principalmente entre 2000 e 2015, ateste uma superioridade da citologia em meio líquido em relação ao método convencional para o rastreio do câncer de colo de útero e lesões precursoras com maior impeditivo sendo o custo inerente ao método, como exposto nos levantamentos bibliográficos sobre o tema nesse período (Girianelli et al, 2004; Anschau \& Gonçalves, 2006; Stabile et al, 2012; Santos et al, 2014; Heise \& Lima, 2016;), a realidade é que no recorte trabalhado nesse artigo apenas os artigos apresentados anteriormente e o artigo de Flora e Colturato (2020), sobre a capacidade de rastreamento do câncer de colo de útero e lesões precursoras pelos dois métodos, que apenas reafirmam a tendência do debate descrevendo as vantagens já descritas como a maior precisão, clareza de lâmina e aproveitamento de esfregaços frente ao custo com o equipamento e readequação de pessoal, debruçam-se sobre o tema. 
Figura 3 - Vantagens e desvantagens da citologia em meio líquido.

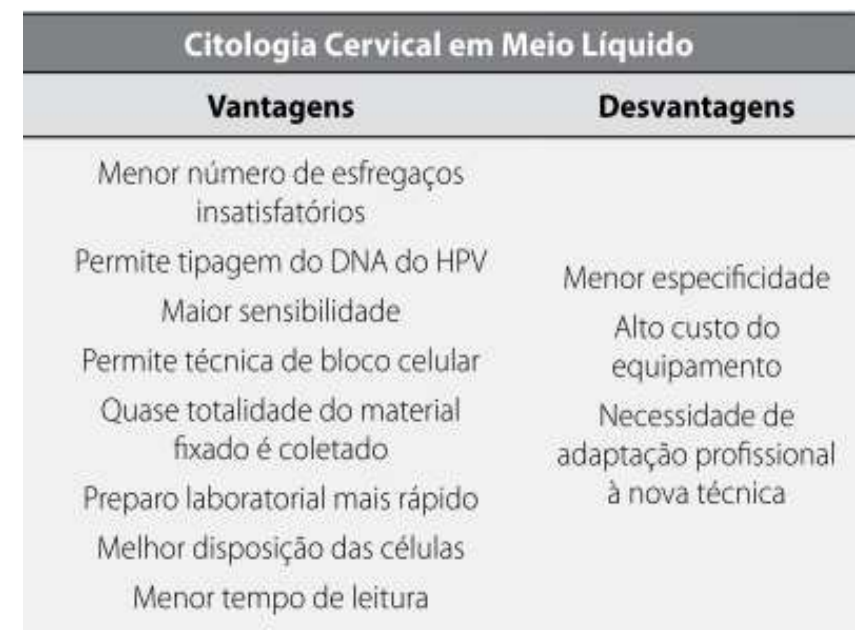

Fonte: Monteiro et al (2017, p.112).

\section{Conclusão}

Em vista do que foi apresentado, a citologia em meio líquida é sempre preferível para facilitar o trabalho do citologista e permitir um diagnóstico mais seguro para a mulher, mas que, simultaneamente, a citologia convencional por ser mais barata e necessitar de menos infraestrutura, tem em seu favor a acessibilidade, o que faz dela útil para avaliações e diagnósticos em situações ou ambientes em que a citologia em meio líquido não seja possível.

As vantagens da citologia em meio líquido, em síntese, são a facilitação de visualização das células fixadas na lâmina, o que permite uma alta precisão e sensibilidade que levam a diagnósticos mais seguros com baixa taxa de falsos-negativos, o melhor aproveitamento do material coletado com o esfregaço e a possibilidade de utilizá-lo para múltiplas análises com uma só amostra. Suas desvantagens estão ligadas ao treinamento e adaptação dos técnicos laboratoriais ao procedimento e ao custo inerente ao método, principalmente relativo à obtenção dos equipamentos que, sendo mais sofisticados, são também mais caros e de manutenção com custo elevado.

A citologia convencional, entretanto, tem como principal vantagem a simplicidade da estrutura necessária para realização da análise, o que permite a execução do exame e diagnóstico mesmo em lugares com infraestrutura básica ou precária. Os pontos negativos são ligados à baixa precisão da qual decorre uma taxa razoavelmente alta de falsos-negativos e a alta taxa de esfregaços com coleta inadequada, o que aumenta o custo da análise e diminui sua eficiência ao gastar tempo para refazer a coleta.

Assim faz-se necessário uma vontade política para que sejam implantados os melhores métodos segundo às condições de cada região coberta pelo programa de Citopatologia cervical de cada localidade. Sempre com intuito de atingir uma melhor cobertura para prevenção do câncer de colo de útero

\section{Referências}

Anschau, F. \& Gonçalves, M. A. G. (2006). Citologia cervical em meio líquido versus citologia convencional. Femina, 34(5), 329-335.

Araujo, D. V. (2019). Portaria No 63 de 12 de dezembro de 2019. Brasília: Diário Oficial da União ${ }^{\circ} 242,420$.

Correa, P. (2008) The war against cervical cancer in Latin America and the Caribbean. Triumph of the scientists. Challenge for the community. Rochester: Vaccine, 265.

Crosseti, M. G. O. (2012). Revisão integrativa de pesquisa na enfermagem o rigor cientifico que lhe é exigido. Revista Gaúcha de Enfermagem. 33(2), 8-9. 
Flora, V. M. S. \& Colturato, P. L. (2020) Estudo comparativo entre citologia oncótica cérvico- vaginal convencional e em meio líquido para rastreamento de câncer do colo do útero e lesões precursoras. Revista Científica Eletrônica de Ciências Aplicadas da FAIT, 2.

Franco, E. L. Prefácio, pp. VII-VIII. In: Consolaro; M. E. L. \& Maria-Engler, S. S. (2014). Citologia clínica cérvico-vaginal: texto e atlas. Editora Roca, 2014.

Girianelli, V. R., Thuler, L. S., Szklo, M.; Donato, A., Zardo, L. M. G.; Lozana, J. A., Almeida Neto, O. F., Carvalho, A. C. L., Matos, J. H. \& Figueiredo, V. (2004). Comparação do desempenho do teste de captura híbrida II para HPV, citologia em meio líquido e citologia convencional na detecção precoce do câncer do colo do útero e de suas lesões precursoras no Rio de Janeiro, Brasil. Revista Brasileira de Cancerologia, 50(3), $225-226$.

Heise, A., \& Lima, A. P. W. (2016). Citopatologia convencional e citologia em meio líquido: uma revisão integrativa. Curitiba: Revista Saúde e Desenvolvimento, $10(5), 208-221$

IDSUS. Razão entre exames citopatológicos do colo do útero em mulheres de 25 a 59 anos e população feminina da mesma faixa etária e local de residência. $<$ http://idsus.saude.gov.br/ficha5s.html>.

Liga Amazonense Contra o Câncer. Taxa de câncer de colo uterino no Amazonas é 102\% maior que a média brasileira. <https://www.laccam.org.br/taxa-decancer-de-colo-uterino-no-amazonas-e-102-maior-que-a-media-brasileira/>.

Martins, T. R. (2016). Citologia líquida e teste molecular para HPV de alto risco: avaliação de novas modalidades de rastreio para prevenção de câncer de colo do útero na rede pública de Saúde do Estado de São Paulo. São Paulo: Faculdade de Medicina - Universidade de São Paulo.

Ministério da Saúde. (2019). Relatório de recomendação da citologia em meio líquido para rastreamento do câncer de colo de útero e lesões precursoras. Brasília: Ministério da Saúde.

Monteiro, C. S., Pascoal-Xavier, M. A., Monteiro, M. V. C. \& Silva-Filho, A. L. (2017). Avaliação crítica do papel da citologia cervical em meio líquido no rastreamento do câncer do colo uterino.: Femina, 45(2), 110-113.

Nakagawa, J. T. T., Schirmer, J. \& Barbieri, M. (2010). Vírus HPV e câncer de colo de útero. Brasília: Revista Brasileira de Enfermagem, 64(2), 307-311.

Oliveira, H. M., Gonçalves, M. J. F. \& Pires, R. O. M. (2011). Caracterização da Estratégia Saúde da Família no Estado do Amazonas, Brasil: análise da implantação e impacto. Rio de Janeiro: Caderno de Saúde Pública, 27(1), 35-45.

Rocha, L. B. (2016). Estudo comparativo entre os métodos de citologia convencional e citologia em meio líquido para diagnosticar as lesões precoces do câncer de colo uterino em um laboratório privado no município de Criciúma. Criciúma: Faculdade do Extremo Sul Catarinense.

Sampaio, S. C. A. (2015). Identificação de HPV de alto risco oncogênico em citologia em meio líquido com atipias escamosas e carcinoma escamoso. Fortaleza: Universidade Federal do Ceará.

Santos, L. A., Silvério, A. S. D. \& Messora, L. B. (2014). Comparação do desempenho da citopatologia convencional e citologia em meio liquido na detecção de lesões: uma revisão sistemática. Três Corações: Revista da Universidade Vale do Rio Verde, 12(1), 99-107.

Silva, I. R., Silva, M. S., Pinheiro, G. J., Ramos, R., Mendonça, E. G. \& Rosa, E. C. C. C. (2021). Exame citopatológico na identificação das principais lesões cérvico-vaginais. Ponta Grossa: Condições teórico-práticas da biomedicina no Brasil, 19-33.

Stabile, S. A. B., Evangelista, D. H. R., Talamonte, V. H., Lippi, U. G. \& Lopes, R. G. C (2012). Estudo comparativo dos resultados obtidos pela citologia oncótica cérvico-vaginal convencional e pela citologia em meio líquido. Einstein, 10(4), 466-472.

Storti Filho, A. \& Pereira, M. W. Técnicas de processamento e rastreamento dos esfregaços citológicos cérvico-vaginais In: Consolaro; M. E. L. \& Maria-Engler, S. S. (2014) Citologia clínica cérvico-vaginal: texto e atlas, 43-52, Editora Roca.

Zonta, M. A. Novas metodologias em citologia cérvico-vaginal. In: Consolaro; M. E. L. \& Maria-Engler, S. S. (2014) Citologia clínica cérvico-vaginal: texto e atlas, 43-52, Editora Roca. 